\title{
O compromisso duplo de um ambulatório naval especializado em dependência química: com os pacientes e com a instituição
}

\author{
The dual commitment of an outpatient clinic specialized \\ in chemical dependency of the Brazilian Navy: \\ to the patients and to the institution
}

Elizabeth Espindola Halpern ${ }^{1}$

Ligia Costa Leite ${ }^{1}$

\footnotetext{
${ }^{1}$ Instituto de Psiquiatria, Universidade Federal do Rio de Janeiro. R. Botucatu 460/ bl. 4/206, Grajaú. 20541-340 Rio de Janeiro RJ Brasil. espindolahalpern@ yahoo.com.br
}

\begin{abstract}
A pioneering study conducted at the Center for Chemical Dependency (CEDEQ) of the Brazilian Navy (MB), by means of an ethnographic study with participant observation, investigated the influence of MB in the identification of alcoholism among patients. This article presents one of the research results, namely the dual commitment of this Outpatient Clinic to the patients and to the institution. The results encompass topics such as the organization and functioning of CEDEQ, therapeutic contract, anonymity and confidentiality, discharge, relapses, readmission and abandonments, secondary gains, "scams" and sanctions in addition to the ambiguous perceptions about treatment. In essence, these findings clarify a little more about the institutional intricacies that contribute to lead many patients to alcoholism.
\end{abstract}

Key words Qualitative research, Researcher-subject relations, Alcoholism
Resumo Um estudo pioneiro no Centro de Dependência Química (CEDEQ) da Marinha do Brasil (MB), por meio de uma etnografia, com observação participante, investigou a influência da MB na construção do alcoolismo dos pacientes. Este artigo apresenta um dos resultados da pesquisa, o duplo compromisso deste Ambulatório, com os pacientes e com a instituição. Os resultados abarcam temas como a organização e o funcionamento do CEDEQ, contrato terapêutico, anonimato e sigilo, altas, recaídas, abandonos $e$ readmissão, ganhos secundários, "golpes" e sanções, além das percepções ambíguas sobre o tratamento. Em suma, tais achados esclarecem um pouco mais sobre os meandros institucionais que colaboram para a constituição do alcoolismo de muitos pacientes.

Palavras-chave Pesquisa qualitativa, Relações pesquisador-sujeito, Alcoolismo 


\section{Introdução}

Este artigo apresenta um dos resultados de um estudo inaugural realizado no Centro de Dependência Química (CEDEQ) da Marinha do Brasil (MB), cujo objetivo central foi investigar a influência desta instituição na construção do alcoolismo dos pacientes. Nesta oportunidade será discutido o fato de o CEDEQ ter um duplo compromisso, com os pacientes e com a instituição, um tema identificado na pesquisa presente no tratamento.

\section{Método, campo da pesquisa e público investigado}

Realizou-se uma pesquisa qualitativa, por meio de uma etnografia densa ${ }^{1,2}$ com observação participante $^{3,4}$ no CEDEQ, de 2005 a 2009, e em dois grupos terapêuticos, em 2010, durante 24 sessões. Os pacientes observados eram militares, do gênero masculino, com idades entre 21 e 62 anos, e participavam da etapa Motivacional do tratamento.

Por serem grupos abertos, em média, havia cerca de dez pacientes em cada grupo. Registros em um caderno de campo incluíram os dados sobre o funcionamento do CEDEQ e as opiniões emitidas espontaneamente pelos pacientes e, para não prejudicar o fluxo da terapêutica grupal, anotações gerais foram realizadas durante a terapia, já que a pesquisadora se manteve como observadora. Adiante, os registros foram organizados, apreendendo o âmago das informações ${ }^{5}$. A eleição do CEDEQ como campo de estudo ocorreu por ser a principal referência do tratamento da dependência química na $\mathrm{MB}$, local onde se dá o entrelace entre o álcool e o trabalho, já que a maioria dos pacientes faz referência à presença do álcool durante a jornada laborativa.

Quanto à amostragem, a coleta, análise e interpretação dos dados, elas ocorreram de forma interativa (circular), não sequencial ${ }^{6-8}$, admitindo a realização de feedback loops (retroalimentação) ${ }^{9}$. Em vez de ter que cumprir um roteiro de forma linear, as etapas fluíram de modo dinâmico.

A etnografia densa possibilitou o desenvolvimento de uma aprendizagem reflexiva alicerçada na perspectiva interacionista ${ }^{10}$, considerando que os indivíduos são produto da interação social ${ }^{11,12}$. O emprego da etnografia viabilizou a compreensão da realidade dos pacientes, incluindo questões como opressão, conflito, luta e poder ${ }^{13}$, descortinando em que medida a MB participou da constituição do habitus alcoólico ${ }^{14}$. O uso da etnografia crítica $^{15}$, por sua vez, permitiu a inspeção de organizações como a Marinha, examinando seus contextos: histórico, social, cultural e político $^{6}$. O estudo etnográfico legitimou a longa imersão no campo, iniciado em 2005, quando a primeira autora, sem definições rígidas ou apriorísticas, iniciou observações e reflexões sobre os significados do alcoolismo no ambiente de trabalho naval. Por meio de um "estado etnográfico"16, ou melhor, um posicionamento de estranhamento, ela mergulhou no universo, nos códigos e linguagens dos outros, apreendendo as regras, costumes e convenções que governam a vida do grupo estudado.

A pesquisa foi deferida pelo Comitê de Ética em Pesquisa da MB.

\section{Resultados}

Os resultados relativos ao compromisso duplo do CEDEQ, com a MB e com os pacientes, serão apresentados a seguir, divididos nos seguintes tópicos: (1) organização e funcionamento do CEDEQ; (2) o contrato terapêutico; (3) anonimato e sigilo; (4) altas, recaídas, abandonos e readmissão no tratamento; (5) ganhos secundários, "golpes" e sanções; e (6) percepções ambíguas sobre o tratamento. Acredita-se que tais achados, oriundos da etnografia, esclareçam um pouco mais sobre os meandros institucionais que colaboram para entender a dinâmica da constituição do alcoolismo de muitos pacientes militares.

\section{Organização e funcionamento do CEDEQ}

O CEDEQ, inaugurado em 1997, representou uma iniciativa pioneira da MB nas Forças Armadas brasileiras. Apesar de a Marinha ter um efetivo de 59.600 indivíduos, o número de militares em tratamento, ao longo dos seus 17 anos de funcionamento, nunca foi superior a 50 pacientes/ ano. Embora aberto a todos os militares da MB, a maior parte dos pacientes pertence à carreira das Praças (termo empregado no feminino), uma maioria numérica da organização que compõe a base da pirâmide hierárquica. Os Oficiais, por sua vez, raramente frequentam este Centro, optando por consultas particulares.

O encaminhamento pode ocorrer voluntariamente, por um profissional da saúde, por determinação de sua OM (Organização Militar) ou por ordem judicial. Porém, a admissão no programa de tratamento depende da avaliação diag- 
nóstica com a equipe, levando em conta alguns critérios: o padrão de uso da substância, o grau de comprometimento físico, psíquico, social, familiar, profissional e sua capacidade de aderir ao tratamento em grupo. A presença de comorbidades, tais como transtornos de personalidade, psicoses, comportamento antissocial, transtornos psicossexuais, limitações orgânicas graves e cognitivas, além de simulação, podem impedir a participação no tratamento grupal.

O tratamento no CEDEQ privilegia a grupoterapia ao longo de cinco etapas: grupo Motivacional, Fases I, II, III e grupo de Consolidação. As sessões ocorrem duas vezes por semana, com duas horas de duração. As etapas duram em torno de quatro meses, por um período total de, no mínimo, um ano e meio, conforme a evolução individual. Espera-se que, ao longo do tratamento, o indivíduo alcance a abstinência e mude suas formas de agir e pensar. As fases possuem um número mínimo de sessões e de atividades, embasando-se nas técnicas comportamentais, nos 12 Passos e nas 12 Tradições dos Alcoólicos Anôni$\operatorname{mos}^{17}$. Ademais, são apresentados filmes e livros relacionados ao tema da dependência química, seguidos de debates e palestras, objetivando, não apenas informar, mas criar vínculos para que a adesão seja intensificada. O grupo Motivacional, que corresponde à fase inicial do programa, visa estimular a adesão ao tratamento, encorajando a sobriedade.

Tendo em vista que a maioria dos integrantes da equipe foi designada para atuar no CEDEQ por determinação superior, sem ter conhecimento prévio sobre como deveriam estruturar o atendimento, houve a contratação temporária de consultores externos, logo após a inauguração, para ajudar a delinear o formato do tratamento. Algumas estratégias ainda existem na atualidade, sobretudo o tratamento em grupo, progredindo em fases.

No decorrer desses anos, devido às transferências para outras $\mathrm{OM}$, os membros da equipe não continuaram os mesmos. Cada profissional que entra na equipe precisa se adaptar ao modelo terapêutico e à clientela, tendo que se familiarizar com os desafios atinentes ao tema da dependência química, somados às peculiaridades da vida militar. Diferente do enquadre terapêutico das consultas convencionais, os aspectos administrativos, burocráticos e até jurídicos envolvidos requerem uma atenção diferenciada.

A criação do CEDEQ não se esgotou com a assinatura de uma Portaria, mas vem sendo diariamente consolidada ao longo de um percurso que envolve dúvidas, erros e acertos. Embora o profissional tenha liberdade de conduzir o grupo conforme sua formação pessoal, os profissionais tendem a incorporar o saber e a prática baseados nos passos dos AA. Inclusive, os pacientes e terapeutas assimilam os jargões e os pontos de vista dos grupos anônimos, sobretudo quando alguns pacientes passam a frequentá-los paralelamente.

\section{$O$ contrato terapêutico}

Um contrato terapêutico formaliza o ingresso paciente, sua concordância com as regras e compromisso com o tratamento. Ao mesmo tempo, ele ajuda a dar maior crédito ao CEDEQ perante suas OM, muitas vezes céticas sobre sua relevância. Mais do que incitar o paciente a se sentir vinculado ao tratamento em si, o contrato produz efeitos na própria $\mathrm{MB}$, alheia ao Ambulatório que criou. O contrato salvaguarda o espaço terapêutico, por vezes exibido a colegas e superiores como prova de que têm um compromisso a ser acatado.

Conquanto o contrato tenha sido revisto desde a sua primeira versão, ele ainda tem uma feição normativa acentuada, assemelhando-se aos documentos navais, inclusive com ênfase nos critérios de desligamento. Porém, este item não é seguido à risca, uma vez que o desligamento sumário deveria ocorrer mediante a falta a três sessões consecutivas, sem justificativa plausível, em qualquer fase do tratamento, e por sua não adesão, em virtude de problemas de conduta do ponto de vista ético, moral, administrativo ou militar, com atitude desrespeitosa dirigida a qualquer integrante da equipe ou paciente.

O CEDEQ oficializa a inclusão dos pacientes no tratamento por mensagem, uma forma de comunicação peculiar da MB. Tal como um telegrama, um texto objetivo é redigido pelo CEDEQ à OM do militar, propondo o início do tratamento, informando a data e hora das sessões. Ao converter esta decisão terapêutica em linguagem naval, obedecendo às regras da organização, o CEDEQ se impõe como uma instância com poder decisório, coibindo tentativas das $\mathrm{OM}$ de tolherem a frequência do militar às consultas. Isso ajuda a aumentar seu prestígio e credibilidade na MB.

Ao tomar conhecimento de que medidas administrativas serão tomadas para que ele seja admitido no CEDEQ, o neófito costuma se sentir desconfortável, exposto e até resignado. $\mathrm{Na}$ prática, o conteúdo da mensagem pode acabar "vazando" indevidamente, espalhando a notícia de que o "fulano de tal" foi incluído no CEDEQ 
e que é "cachaceiro". Porém, tal "revelação" não chega a ser uma novidade, porquanto seus episódios de intoxicação costumam ser de conhecimento geral. A diferença é que a mensagem oficializa a situação e confere existência àquilo o que já era sabido, mas abafado, dando margem à maledicência. Se, por um lado, a mensagem o expõe, por outro, o protege, tendo em vista as tentativas insistentes da administração naval para que o militar abandone o tratamento e volte ao trabalho, mão de obra que não pode ser desperdiçada por algumas horas semanais. Ademais, a equipe busca a aquiescência dos superiores hierárquicos do militar como uma tática para implicá-los no processo. Em seguida, a OM do militar responderá, por meio de mensagem, sua concordância, tornando-a corresponsável pelo processo de recuperação. Considerando que as sessões ocorrem durante o expediente, a ausência injustificada precisa ser comunicada à $\mathrm{OM}$ do paciente. Sua presença no CEDEQ faz parte de um acordo que se faz na esfera militar, até porque, no horário do grupo, ele deverá estar na sessão.

Em geral, os pacientes externam desagrado por se sentirem controlados quando seus Chefes querem notícias do tratamento e anseiam pela alta: O Diretor me deu todo apoio, até conversou comigo no gabinete. Eu sei que ele fica me 'filmando' [vigiando], quer saber se tenho ido ao CEDEQ. É tudo 'fachada' [aparência], ele tem medo de eu dar problema no serviço. A sensação de serem "filmados"18,19 (vigiados) pode ter fundamento. Embora algumas $\mathrm{OM}$ queiram ter notícias sobre seus militares, as respostas são fornecidas por escrito, respeitando os trâmites burocráticos, atendo-se aos dados sobre frequência e restrições laborativas.

\section{Anonimato e sigilo}

Ao contrário do que ocorre nos grupos anônimos, no CEDEQ não há anonimato; afinal, todos fazem parte do mesmo universo. Todavia, quanto ao sigilo, ele nunca é rompido, apesar dos temores iniciais manifestados pelos pacientes. Contudo, nos primeiros anos de existência do CEDEQ, houve tentativas de se obter informações dos pacientes, por parte dos seus Chefes, das esposas e familiares. O confronto foi uma estratégia aplicada por alguns terapeutas no passado, juntando a família, o Encarregado e o próprio paciente para extrair a "verdade" e desmoronar a "famigerada negação". Com o passar dos anos, houve uma reversão dessa visão, passando a estimular o sujeito a construir um espaço de con- fiança para querer se abrir, trazendo à tona a sua verdade, sem confrontá-la com informações externas ao setting terapêutico.

\section{Altas, recaídas abandonos \\ e readmissão no tratamento}

Apesar dos desafios para fazerem o tratamento, alguns conseguem concluí-lo, recebendo alta. Em razão das peculiaridades desse transtorno, há o costume deles retornarem, sobretudo pelas múltiplas circunstâncias que geram recaídas. Dependendo do caso, o militar que regressa ao $\mathrm{CE}$ DEQ pode ser readmitido na etapa que a equipe julgar mais apropriada à sua condição. Existe flexibilidade quanto aos parâmetros de readmissão. É comum que alguns acabem aderindo ao tratamento, obtendo êxito após várias tentativas de se tratarem. Geralmente, eles se empenham pela recuperação integral após inúmeras desistências e grandes perdas. Ao se sentirem mais amadurecidos e fortes para lutarem pela sobriedade e para reverterem um cenário de prejuízos, conseguem concluir o programa completo de tratamento. A seguir, eles são convidados a permanecerem no grupo de pós-tratamento por tempo indeterminado, o Grupo de Consolidação.

A despeito dos esforços da equipe para que permaneçam no CEDEQ, faltas e abandonos regulares fazem parte do cotidiano. Apesar de o contrato estabelecer critérios para a inclusão e para o desligamento, os pacientes entram e saem do CEDEQ inúmeras vezes.

Quando um paciente abandona o tratamento, geralmente ele acaba retomando-o desde o início, ainda que, um dia, ele tivesse conseguido alcançar estágios mais “avançados”. Logo, muitos pacientes não são, de fato, neófitos, mas reincidentes. De volta ao grupo, como em um confessionário, relatam suas desventuras durante o afastamento, admitem fraquezas, o apego às substâncias e compartilham as dificuldades em dizerem "não" aos convites para beber. $\mathrm{O}$ reingresso pode ser experimentado como uma "volta ao lar": muitos se sentem em casa, acolhidos, recebidos com fortes abraços e apertos de mão, laços construídos, não apenas nas rotinas laborativas das unidades militares onde serviram juntos, mas também estabelecidos no CEDEQ, refúgio onde admitem seus vexames e travessuras. Esse é um dos muitos momentos em que o atendimento em grupo se mostra mais eficaz do que o individual. O espírito de corpo sustenta fraternalmente companheiros de farda e de copo: a "Marinha-mãe" misericordiosa acolhe o retorno dos “filhos pródigos". Esta é uma 
faceta da MB que não abandona os "filhos marginais” que gerou, dá-lhes uma segunda chance. Em seu seio, oferece a reabilitação, o suporte e a estrutura que lhes falta em razão da corrosão das substâncias nefastas que fizeram ruir seus frágeis alicerces, desde sua gênese familiar.

Embora muitos que retornam tenham rompido com o contrato por terem ultrapassado o número máximo de faltas ou abandonos previstos, dificilmente as portas se fecham para eles. $\mathrm{O}$ pedido de socorro, a evidência concreta de prejuízos irremediáveis, a crença na recuperação, são alguns dos ingredientes capazes de alterar a decisão contratual de cortá-los do tratamento. $\mathrm{Na}$ prática, a equipe se mostra disposta a reintegrá -los, mesmo que as chances de mudanças sejam remotas.

\section{Ganhos secundários, "golpes” e sanções}

Existem ganhos secundários evidentes ao se tornarem pacientes, causando irritação em alguns administradores navais. $\mathrm{O}$ afastamento parcial não se limita apenas ao número de horas ausentes da OM, mas também se refere às usuais restrições laborativas estipuladas pelo uso de medicação controlada, ou melhor, mesmo quando eles estão presentes na OM, deixam de realizar as atividades, a saber: participar de manobras e formaturas, dar serviço armado e de pernoite, embarcar, entre outras. Com efeito, eles acabam sobrecarregando outras Praças, sendo um a menos para dividir o fardo, acentuando o rancor. Porém, dependendo da ocasião, as restrições podem atrapalhar a progressão na carreira, mormente na época em que são avaliados para a promoção, porquanto precisam estar integralmente aptos para o serviço ativo. Logo, imploram para que as restrições sejam finalizadas. Para aplacar o descontentamento geral e a sensação de injustiça, muitos Chefes atribuem conceitos semestrais inferiores aos que ficaram mais tempo ausentes da OM ou que têm restrições laborativas. Por conseguinte, os pacientes costumam receber conceitos mais baixos. Por outro lado, esse procedimento tende a ser aplicado automaticamente, ainda que a qualidade do serviço do militar tenha sido suficientemente boa para fazer jus a um conceito alto. Todavia, os critérios de avaliação parecem estar mais relacionados à frequência/presença na unidade militar. Interessa que o indivíduo esteja em estado de prontidão: Eles baixam o meu conceito, não só porque o meu serviço é na base da produtividade! Eles querem o sujeito lá dentro, mesmo sem ter o que fazer. Eles se ressentem quando o indivíduo assume que vai se tratar. Afastar-se das rotinas diárias para ir ao grupo implica em uma inegável exposição do indivíduo, ainda mais quando sua carreira já está comprometida pela sucessão de falhas. Muitos Chefes e colegas de trabalho compreendem a importância do tratamento e sua necessidade, sendo solidários. Todavia, pelo desconhecimento, preconceitos e mitos sobre a adicção, o indivíduo recebe apoio com reservas:

Pra eu chegar aqui não dá só pra bater na porta do CEDEQ pra entrar. Tive que contar minha história pra mais de dez pessoas, até conseguir chegar aqui. No terceiro, já tava quase desistindo, não quero mais falar com ninguém. Pra vir, você tem que se expor.

Em uma instituição militar, para fazer contato com o mais antigo, é preciso "seguir canal", galgando cada instância da cadeia hierárquica. A história deste paciente precisou ser exposta a todos os que estavam "acima" dele. A fama negativa que muitos constroem sobre si mesmos no decorrer dos anos requer maiores explicações e comprovações. Forma-se um círculo vicioso no qual o estigma de malandro ou irresponsável vai aderindo progressivamente, quase impossível de ser superado. Por isso, muitos consideram que o CEDEQ serve de refúgio ao "embusteiro" que está "enrolando" a equipe. Muitos manipulam a equipe, sobretudo para se ausentarem do quartel. Há um consenso de que o militar estaria se "escamando”, ou seja, tirando proveito do diagnóstico de dependente químico para se esquivar das obrigações. Outros confessam que usam esse tipo de ardil para terem um ganho colateral quando passam a pertencer à categoria de "doentes". Em geral, muitos não se importam com sua reputação sofrível, preferem as vantagens desta situação.

A mentira é um tema recorrente nos grupos, o que leva muitos pacientes a denunciarem colegas que estão enganando o CEDEQ e suas OM. Essas notícias se espalham e tendem a abalar a reputação deste Centro, a seriedade do tratamento dos outros pacientes, consolidando a opinião de que os usuários de drogas devem ser "tratados" pela via administrativa/militar. Um paciente esclareceu: Alguns Oficiais aceitam que é doença porque a OMS [Organização Mundial de Saúde] $e$ o Comando da Marinha aceitam, mas eles têm um rancor; acham que é 'chute'! [golpe] A gente vai se sentindo menosprezado. Após a adesão ao tratamento, quando mudam o padrão de comportamento, confessam, espontaneamente, a aplicação desses "golpes".

Alguns pacientes tiram partido da liberação para irem ao tratamento e usam esses horários 
para outros interesses. Ao reportar a ausência deles por mensagem, o CEDEQ oficializa que não é conivente com essas "fugas" e demonstra que a equipe conduz o tratamento com seriedade. Para minimizar os efeitos negativos dessas "saídas", a decisão compartilhada pela equipe é a de explicitar tal situação, nunca mascará-la. As observações participantes demonstraram que a adoção de uma postura transparente reforçava a confiança dos pacientes com a própria equipe e a crença no tratamento.

Cientes das regras claras do contrato terapêutico, espera-se dissuadir ou minimizar tais "golpes", pois, perante sua comprovação, seus Chefes poderão tomar as medidas administrativas que julgarem cabíveis. Muitos superiores hierárquicos se sentem inseguros quanto à adequação de aplicarem sansões ao militar que se encontra no CEDEQ, como se a terapia e a punição não pudessem coexistir. Contatos telefônicos são comuns para esclarecer sobre como devem se conduzir, indagando se a punição atrapalharia a terapia. Na realidade, cada caso precisa ser analisado isoladamente, não há uma regra de aplicação geral. Tentativas de lograr o tratamento são reportadas pelos próprios autores, embalados pelo espírito de confiança no grupo. Há casos em que os integrantes comentam que alguns colegas estão sendo desonestos com o CEDEQ arrumando “desculpas esfarrapadas” para suas ausências.

As mensagens informando as faltas não justificadas já deflagraram a tomada de decisões administrativas de seus Encarregados, colocando -os no "livro" (Livro de Registro de Contravenções Disciplinares, documento onde ficam registrados: o resumo do histórico da falta cometida, o seu enquadramento no regulamento disciplinar, as circunstâncias atenuantes ou agravantes e a pena imposta). Após o julgamento do Comando, muitos são condenados e recebem alguma punição. Enquanto para alguns esta experiência ajudou a dar limites e maior comprometimento com sua recuperação, para outros, trouxe ressentimento. A maioria acaba reconhecendo que trapaceou.

Ao construírem a própria má fama e trapacearem o tratamento, em algum nível, comprometem a reputação do CEDEQ. Sem dúvida, o número de exemplos negativos supera o de êxitos; em outras palavras, poucos são os pacientes que se recuperaram para servirem de modelo e de estímulo. Interessante observar que os próprios militares que ingressam descrentes ou dispostos a manipular, fugindo das sessões, deixam rastros fáceis de serem identificados. Existem inúmeros relatos de eles serem vistos bêbados nos bares situados nos arredores de suas OM, ou nas esquinas próximas ao próprio $1^{\circ}$ Distrito Naval, no centro da cidade do Rio de Janeiro, nas imediações do HCM. Outros confidenciam que saem direto das sessões para se entregarem à cachaça, sem terem condições de retornarem aos quartéis ou navios pelo estado de intoxicação.

\section{Percepções ambíguas sobre o tratamento}

Constatou-se a ambiguidade de percepções que circula em várias esferas sobre o significado da dependência química, despertando interrogações que são preenchidas por mitos, preconceitos e desinformações. Pacientes, familiares, colegas de trabalho, superiores hierárquicos e subordinados, todos se mostram incertos sobre como se conduzir diante desta questão. O CEDEQ também pode ser uma incógnita, porquanto sua natureza responde por isso, justapondo a sua vocação terapêutica e militar: Eu não queria ir pro CEDEQ. O CEDEQ é muito 'por ordem'. Tem sempre regras, muita regra demais pra minha cabeça.

Este Ambulatório tende a ser visto com reservas, inclusive pelos dependentes químicos, obstando a busca por auxílio. Embora muitos militares tenham vontade de se tratar, paira uma dúvida sobre a sua real missão. Geralmente, os militares temem que o "militarismo" prevaleça, devassando suas privacidades. Outros, conformados com as punições recebidas, não se sentem melindrados com a exposição de suas "fraquezas". $\mathrm{Na}$ verdade, eles estão familiarizados com a atuação do Serviço de Informações, bem como com a presença dos "Secretas de Marinha" (militares incumbidos dessa função). Por isso, mostram-se indiferentes com os procedimentos administrativos do CEDEQ, com a tramitação de mensagens, pareceres e ofícios informando o seu status no tratamento para seus Comandos. Justificam que não se importam com as repercussões negativas para suas carreiras porque já atingiram o "fundo do poço" e não têm mais nada a perder. No caso dos novatos, percebe-se sentimentos de desconfiança ou temor:

Eu não sabia nem que existia o CEDEQ! Não sabia que a Marinha tinha isso aí. No começo eu fiquei meio assim... [hesitante]. Porque, eu vou ser sincero, né, desculpa a sinceridade! Mas eu pensei que o CEDEQ fosse 'de Marinha'. Aí não ia dar muito certo, porque você é militar, vão achar que você é vagabundo.

Este paciente demonstrou receio sobre qual seria o real papel da equipe, se o CEDEQ era "de 
Marinha”, ou melhor, se estaria comprometido com a instituição ou com os pacientes, para não ser julgado como vagabundo.

Percepções ambivalentes sobre o CEDEQ também são despertadas nas Chefias dos pacientes. Embora este Ambulatório faça parte do organograma naval e atue em prol da tripulação, na prática, as autoridades ficam incomodadas quando têm que liberar seus subordinados para as sessões na hora do expediente. Ainda que ratifiquem sua liberação, um grande número deles se queixa da ausência de suporte. A longa duração da terapia (cerca de um ano e meio) e a frequência (duas vezes por semana) acabam irritando os colegas de trabalho. Com o passar do tempo, aumenta a expectativa geral de que deem sinais de "cura" e que retomem suas funções com a maior brevidade possível, minimizando os prejuízos ao serviço: Quando o indivíduo vem pro CEDEQ e deixa de vir pra bordo, a faxina [tarefa] se acumula, especialmente pra especialidade da Praça que trabalha com produtividade.

É compreensível que a administração naval tenha interesse em recuperar essa força de trabalho, não apenas por necessidade de serviço, mas para aplacar a pressão dos companheiros que, ressentidos, foram obrigados a assumir suas tarefas na sua ausência. Em contrapartida, os pacientes também se constrangem por estarem ausentes do serviço; poucos estão dispostos a serem rejeitados e censurados pelos colegas, ainda mais em função do diagnóstico de dependentes químicos, até porque a liberação para irem ao CEDEQ invariavelmente provoca a imputação de rótulos, muitos deles vexatórios ${ }^{20}$. Apenas um número reduzido prioriza a sua recuperação, colocando as censuras e os juízos em segundo plano. Muitos acabam solicitando o desligamento antes do término, por acreditarem que, afastados do CEDEQ, poderão recobrar a boa reputação:

Eu queria pedir às Senhoras [terapeutas do grupo] pra ser desligado do CEDEQ. Eu gosto muito daqui, tá me ajudando mesmo! Mas é por causa do conceito [avaliação profissional]. Eles baixaram meu conceito e eu preciso recuperar pra conseguir ser promovido. Se eu continuar vindo pro CEDEQ, nunca vão aumentar o meu conceito; vai prejudicar a minha carreira, sabe?!

Reaver ou conquistar o conceito cinco (as avaliações semestrais de desempenho profissional e pessoal atribuem conceitos de um a cinco aos militares, sendo que o maior e mais almejado é o cinco) pode ser mais importante do que alcançar a sobriedade. A pressão no trabalho ajuda a inverter as prioridades na vida do sujeito. Em nome da aceitação grupal, colocam as necessidades pessoais em segundo plano para evitarem críticas: Nem sempre você encontra reciprocidade do Comandante; às vezes, você se sente um lixo; te tratam com aquela arrogância.

De fato, as razões para eles se tratarem podem ser facilmente deturpadas. Muitos daqueles indivíduos que se tornaram sóbrios iniciaram o tratamento trapaceando e, somente adiante, reconheceram que as mentiras eram prejudiciais a eles mesmos.

\section{Discussão}

A apresentação dos resultados adstritos a este artigo, supracitados, faz parte do rol de achados de um estudo mais abrangente que procurou compreender o alcoolismo enquanto fenômeno, um traço da cultura, cujas funções sociais ou simbólicas mudam de acordo com o contexto de seu uso ${ }^{21,22}$. Na pesquisa maior, verificou-se, para além dos diagnósticos que engessam os indivíduos ao discurso biomédico, a relevância da dimensão sociocultural da dependência do álco$\mathrm{ol}^{23}$ para entender a variedade de processos que participam de sua constituição, inclusive fatores relacionados ao ambiente laboral.

Nesta oportunidade, desejou-se demonstrar que a etnografia e a observação participante evidenciaram aspectos da dinâmica ambulatorial e institucional que permitiram extrair significados sobre a relação entre álcool e trabalho naval ${ }^{14}$. Tal visão relativiza e contextualiza a experiência do etilismo e expande a compreensão sobre como muitos indivíduos passam a ser estigmatizados $^{24}$, recebendo o rótulo de desviantes ${ }^{25}$. Para além dos elementos psicológicos e psiquiátricos em jogo nas sessões grupais, "filigranas" relacionadas às exigências administrativas e militares, tais como as circunstâncias relacionadas às faltas, abandonos e desligamentos, aparentemente sem relevância, ganharam proeminência ao olhar investigador. Ao invés desses acontecimentos serem considerados um estorvo ao "bom andamento" da terapia, eles iluminaram os significados de seu alcoolismo, imbricados aos aspectos laborais peculiares da $\mathrm{MB}^{26}$. As explicações para seus modos de beber não estavam restritas ao funcionamento psíquico ou às histórias familiares, mas disseminadas nos interstícios das sessões, no começo da consulta, ao final da sessão ou em outras oportunidades, enfim, nas franjas do setting terapêutico. Logo, os atrasos às reuniões, por exemplo, ajudaram a entender as razões do "adoecimento" de 
muitos pacientes ${ }^{27}$, elucidando assuntos atinentes às suas adicções. Elementos aparentemente secundários, corriqueiros ou banais que explicavam atrasos às consultas, tais como, óbices no trabalho ou mesmo engarrafamentos, passaram a ser ouvidos com mais atenção. A apresentação da cópia da escala de serviço para justificar a ausência de um paciente a uma reunião, comprovando que ele faltou à terapia porque estava de serviço na hora da consulta, tornou-se um dado de análise. De fato, tais justificativas, verbais ou por escrito, deixaram de ser naturalizadas, compreendendo-se que, nessas ocasiões, os pacientes estavam trazendo à tona questões relativas aos trabalhos marinheiros e sua relação com o seu alcoolismo ${ }^{26}$. Muitos elementos significativos emergem nas brechas desses encontros, trazendo informações que poderiam ter passado despercebidas ao olhar do observador.

A partir da atitude etnográfica, uma maneira de olhar e de construir o relato, uma perspectiva hermenêutica que tenciona capturar a dimensão da experiência, a pesquisa maior constatou a presença de uma crença "blindada" nas tradições navais que induzem o consumo do álcool a bordo, abrindo espaço à reflexão sobre as condições de trabalho do militar que induzem ao beber abusivo ou dependência ${ }^{28}$. Este aspecto remete à relevância da postura filosófica hermenêutica ${ }^{29}$, que valoriza o movimento de se colocar no lugar do outro para compreendê-lo, bem como acredita que as histórias e as biografias têm um significado latente ou profundo, o qual se alcança por meio da interpretação. Porém, o beber na jornada laboral tende a ser uma prática naturalizada ${ }^{30}$ na $\mathrm{MB}$, percepção couraçada contra ressalvas.

\section{A vocação dupla do CEDEQ: terapêutica e militar}

A etnografia e a observação participante evidenciaram que o CEDEQ se divide em duas ordens - terapêutica e militar. Na prática, a equipe e os pacientes estão comprometidos com o sistema naval, inseridos em um dos capilares do organograma institucional e envelopado pela estrutura castrense, porquanto sua estrutura se ancora no arcabouço militar. Portanto, o fato de a pesquisa ter transcorrido em uma unidade militar tem um significado que não deve ser negligenciado. De fato, este Centro é experimentado pelos pacientes como uma extensão de seu espaço laboral, onde compartilham os mesmos códigos, normas e linguagem, onde todos são "colegas de farda", irmanados pelas experiências comuns.
Ademais, constatou-se que, a despeito de o CEDEQ ter nascido para ser um núcleo de tratamento de dependência química, não é mais do que um modesto ambulatório especializado. A ausência de perspectivas de expansão pode ser justificada pelo desinteresse da MB sobre o tema da dependência química.

A linguagem e percepções dos pacientes são impregnadas por um ideário oriundo do discurso hegemônico no CEDEQ e nos AA e NA, inserido paulatinamente em suas visões de mundo. Pautados nos 12 Passos e 12 Tradições, os indivíduos tomam consciência de seus atos e fazem uma revisão em seus comportamentos, sendo responsabilizados pelo seu "adoecimento" e manutenção da sobriedade, frisando que nunca serão "curados". Eles são tidos como "doentes em recuperação" ${ }^{1}$, prevalecendo a ideia de que ser alcoolista significa ser dominado por uma necessidade física que se impõe à própria vontade do indivíduo ${ }^{32}$. Geralmente, as terapeutas orientam os pacientes a se manterem em um estado de permanente vigilância, desconfiando até das "aparentes" melhoras. A expectativa de que eles consigam entrar em abstinência como evidência concreta de reabilitação é um fator importante na terapia, comprovação de que assimilaram o programa de recuperação ${ }^{33}$.

Imerso na cultura naval, o CEDEQ é portavoz dos valores e princípios navais, reproduzindo a cosmovisão institucional que culpabiliza ${ }^{34} \mathrm{o}$ indivíduo pelos seus atos desviantes atrelados à $\operatorname{adicção}^{35}$. O CEDEQ é Marinha, fisicamente localizado no $1^{\circ}$ Distrito Naval, cercado por diversas unidades militares, uma peça da engrenagem naval que deve prestar contas à administração superior sobre o diagnóstico, prognóstico e reabilitação dos pacientes. Trata-se da sua vocação e missão primordiais que se impõem/opõem, de uma forma ou de outra, ao tratamento. Ainda que existam percepções variadas sobre este Ambulatório, na prática, CEDEQ e MB se misturam, ou melhor, constata-se um continuum entre eles, fundindo-se e diferenciando-se: Eu tinha medo da Marinha ficar sabendo. Mas ela acabou sabendo porque a droga tinha controlado minha vida. Mas hoje sei que a Marinha abriu as portas pra mim.

\section{Considerações finais}

Este estudo capturou uma importante faceta da $\mathrm{MB}$, inserida no multivariado contexto em que se dá a constituição do alcoolismo dos pacientes do CEDEQ, a saber, a identificação do duplo 
compromisso deste Centro, com os pacientes e com a instituição. Tal fato ajuda a perceber como o alcoolismo de seu contingente é socialmente e institucionalmente produzido.

Os ensinamentos oriundos do microcosmo do CEDEQ serviram de modelo explicativo, em pequena escala, suscitando induções deste conjunto particular de resultados para um escopo mais amplo. As experiências desses pacientes podem ser cotejadas com outras similares, esclarecendo as vivências de outros indivíduos. "Partese do princípio de que as lições que se aprendem desses casos fornecem muitas informações sobre as experiências da pessoa ou instituição usual"36.
Este tipo de estudo viabiliza a consecução de levantamentos macrossociológicos futuros, dirigidos a um âmbito expandido ${ }^{37}$, em direção a outros segmentos da $\mathrm{MB}$, ou para outros campos que tenham elementos e estruturas similares.

Em suma, a experiência com o álcool se dá em diferentes espaços e momentos nas unidades navais, quando ele cimenta relacionamentos entre "colegas de farda" na OM e no CEDEQ, unindo os pacientes em torno dos testemunhos compartilhados. Na Marinha, o círculo se completa: ironicamente, a instituição se propõe a recuperar aqueles que ela mesma colaborou para adoecer.

\section{Colaboradores}

EE Halpern construiu o artigo a partir da análise e interpretação dos dados oriundos de sua Tese de Doutorado. Ademais, ela foi responsável pela redação e concepção do conteúdo intelectual, análise e interpretação dos dados. LC Leite participou como orientadora da Tese de Doutorado, participando da análise e interpretação dos dados e contribuindo para a concepção do conteúdo intelectual e sua revisão crítica. 
Referências

1. Hughes EC. Introduction: the place of field work in social science. In: Junker BH. Field work: an introduction to social sciences. Chicago: University of Chicago Press; 1960. p. 3-13.

2. Geertz C. A interpretação das culturas. Rio de Janeiro: LTC; 1973.

3. Malinowski B. Argonauts of the Western Pacific. An account of native enterprise and adventure in the archipelagoes of Melanesian New Guinea. Illinois: Waveland Press Inc.; 1922.

4. Minayo MCS. O desafio do conhecimento: pesquisa qualitativa em saúde. São Paulo: Hucitec; 2006.

5. Malinowski B. Argonauts of the Western Pacific. Illinois: Waveland Press Inc.; 1984

6. Fossey E, Harvey C, McDermott F, Davidson L. Understanding and evaluating qualitative research. Aust NZJ Psychiatry 2002; 36(6):717-732.

7. Maxwell J. Qualitative research design: an interactive approach. London: Sage; 1996.

8. Tesch R. Qualitative research: analysis types and softward tools. New York: Falmer; 1990

9. Whitley R, Crawford M. Qualitative research in psychiatry. Can J Psychiatry 2005; 50(2):108-114.

10. Whyte WF. Sociedade da esquina: a estrutura de uma área urbana pobre e degradada. Rio de Janeiro: Zahar; 2005.

11. Mead GH. The individual and the social self: unpublished essays by G. H. Mead. Chicago: University of Chicago Press; 1982.

12. Blumer H. Symbolic interaction: perspective and meth od. Oakland: University of California Press; 1986.

13. Spradley J. The ethnographic interview. Fort Worth, TX Harcourt Brace; 1979.

14. Halpern EE. O "uniforme" e o "copo": a constituição do habitus alcoólico na Marinha do Brasil [tese]. Rio de Janeiro: Universidade Federal do Rio de Janeiro; 2013.

15. Schwandt TA. Qualitative inquiry: a dictionary of terms. Thousand Oaks: Sage; 1997.

16. Duarte LFD, Gomes EC. Três famílias: identidades e trajetórias transgeracionais nas classes populares. Rio de Janeiro: FGV; 2008.

17. Alcoólicos Anônimos. O Grupo de AA: onde tudo come ça. São Paulo: JUNAAB; 1996.

18. Foucault M. Vigiar e punir: nascimento da prisão. Petrópolis: Vozes; 2007.

19. Foucault M. Microfísica do poder. Rio de Janeiro: Graal; 1979.

20. Gaulejac V. As origens da vergonha. São Paulo: Via Lettera Editora e Livraria; 2006.

21. Fainzang S. Curar-se do álcool: antropologia de uma luta contra o alcoolismo. Rio de Janeiro, Niterói: Intertexto; 2007.

22. Douglas M. Constructive drinking: perspectives on drink from Anthropology. Cambridge: Cambridge University Press; 1987.
23. Silva Filho JF, Luce C. O declínio do pai, a mimesis e toxicomania. In: Cruz MS, Ferreira SMB, organizadores. Álcool e drogas: usos, dependência e tratamentos. Rio de Janeiro: IPUB/CUCA; 2001. p. 63-76.

24. Goffman E. Stigma: notes on the management of spoiled identity. Englewood Cliffs: Prentice-Hall; 1963.

25. Becker HS. Outsiders: studies in the sociology of deviance. New York: Free Press; 1963.

26. Halpern EE, Leite LC. A interseção entre os trabalhos marinheiros e o alcoolismo. Rev Psi: Org e Trab 2013 13(2):111-126.

27. Halpern EE, Leite LC. Representações de adoecimento e cura de pacientes do Centro de Dependência Química do Hospital Central da Marinha. Cien Saude Colet 2012; 17(4):1079-1089.

28. Halpern EE, Ferreira SMB, Silva Filho JF. Os efeitos das situações de trabalho na construção do alcoolismo de pacientes militares da Marinha do Brasil. Cad Psicol Soc Trab 2008; 11(2):273-286.

29. Minayo MCS. O desafio do conhecimento: pesquisa qualitativa em saúde. São Paulo: Hucitec; 2006.

30. Halpern EE, Leite LC. Oportunidades de beber a bordo: características do labor naval. Physis 2013; 23(4):12771296.

31. Halpern EE, Leite LC. Representações de adoecimento e cura de pacientes do Centro de Dependência Química do Hospital Central da Marinha. Cien Saude Colet 2012; 17(4):1079-1089.

32. Campos EA. As representações sobre o alcoolismo em uma associação de ex-bebedores: os Alcoólicos Anônimos. Cad Saude Publica 2004; 20(5):1379-1387.

33. Mäkelä K. Alcoholics Anonymous as mutual-help movement: a study in eight societies. Wisconsin: University of Wisconsin Press; 1996.

34. Seligmann-Silva E. Saúde mental e trabalho. In: Costa NR, Tundis S, organizadores. Cidadania e loucura: políticas de saúde mental no Brasil. Petrópolis: Editora Vozes, Abrasco; 1990. p. 217-287.

35. Halpern EE, Leite, LC. The construction of the alcoholic habitus and alcohol consumption in the workplace among military patients of Brazilian Navy. Cad Saude Colet 2001; 19(3):356-365.

36. Yin RK. Estudo de caso: planejamento e métodos. Porto Alegre: Bookman; 2005.

37. Elias N, Scotson JL. Os estabelecidos e os outsiders: sociologia das relações de poder a partir de uma pequena comunidade. Rio de Janeiro: Zahar Editora; 2000.

Artigo apresentado em 05/11/2014

Aprovado em 21/06/2015

Versão final apresentada em 23/06/2015 